University of Nebraska - Lincoln

DigitalCommons@University of Nebraska - Lincoln

Faculty Publications from the Harold W. Manter Laboratory of Parasitology

$1-1950$

\title{
A Contribution to the Study of North American Strigeids (Trematoda)
}

Robert L. Rausch

Arctic Health Research Center, rausch@u.washington.edu

George Dubois

Institut de Zoologie, Université de Neuchâtel, Switzerland

Follow this and additional works at: https://digitalcommons.unl.edu/parasitologyfacpubs

Part of the Parasitology Commons

Rausch, Robert L. and Dubois, George, "A Contribution to the Study of North American Strigeids (Trematoda)" (1950). Faculty Publications from the Harold W. Manter Laboratory of Parasitology. 565. https://digitalcommons.unl.edu/parasitologyfacpubs/565

This Article is brought to you for free and open access by the Parasitology, Harold W. Manter Laboratory of at DigitalCommons@University of Nebraska - Lincoln. It has been accepted for inclusion in Faculty Publications from the Harold W. Manter Laboratory of Parasitology by an authorized administrator of DigitalCommons@University of Nebraska - Lincoln. 
to $0.62 \mathrm{~mm}$ at the level of the bursa copulatrix. The ratio of the length of the posterior segment to that of the anterior segment, which varies from 2.35 to 2.57 in a state of contraction, reaches 2.92 to 3.08 in normally extended specimens.

The examination of longitudinal sections reveals the existence of strong muscle sheaths; these diverge beginning at the region narrowed by the transverse constriction in order to extend into the posterior segment, in particular, to lose themselves there at different points of the ventral, pretesticular region, or to reach the genital cone following the dorsal surface of the body. The character of this musculature is expressed by the contraction and strong curvature of many specimens.

The terminal oral sucker measures 100 to $153 \mu$ long by 85 to $120 \mu$ wide. It is immediately followed by a spherical pharynx, of which the diameter is 100 to $119 \mu$. The ventral sucker, situated at the bottom of the cup formed by the anterior segment in the vicinity of the proteolytic gland, measures 190 to $200 \mu$ by 140 to $160 \mu$.

The posterior segment is characterized by the existence of a well-developed genital cone, and a large bursa copulatrix, of which the pore is terminal; the whole occupies the last third of this part of the body. The ovary, situated between the 21st and the 26th hundredths of the length, recurved in an arch

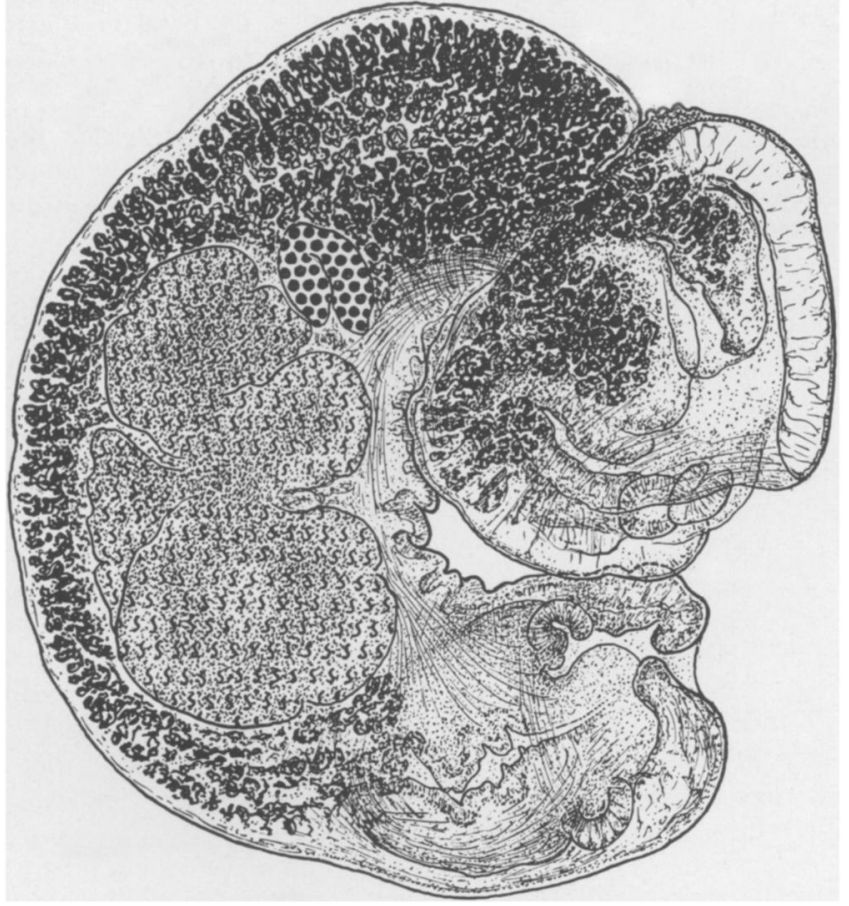

Fig. 1.-Strigea macroconophora n. sp., from Buteo jamaicensis borealis (Gm.). Type specimen; length: $3.09 \mathrm{~mm}$. 
and convex ventrally, measures 130 to $190 \mu$ long along the long axis of the segment, and 250 to $270 \mu$ dorsoventrally. The vitelline glands, amassed mainly in front of the testes, are prolonged under them in order to terminate towards the bursa copulatrix, which is always thus exposed; they penetrate into the anterior segment, constituting an accumulation there, except in the ventral wall, which is totally devoid of them. The eggs measure 90 to $99 \mu$ by 63 to $70 \mu$.

The massive, coarsely-lobed testes are subequal. The first measures 370 to $600 \mu$ in antero-posterior diameter, and 430 to $600 \mu$ in transverse diameter. The corresponding dimensions of the second are 360 to $510 \mu$ by 440 to $595 \mu$. The frontal edge of the first is situated between the 25th and the 33rd hundredths of the length of the posterior segment; the posterior border of the second is situated between the 57th and 71 st hundredths. The sinuous seminal vesicle approaches tangentially the voluminous genital cone, which is 340 to

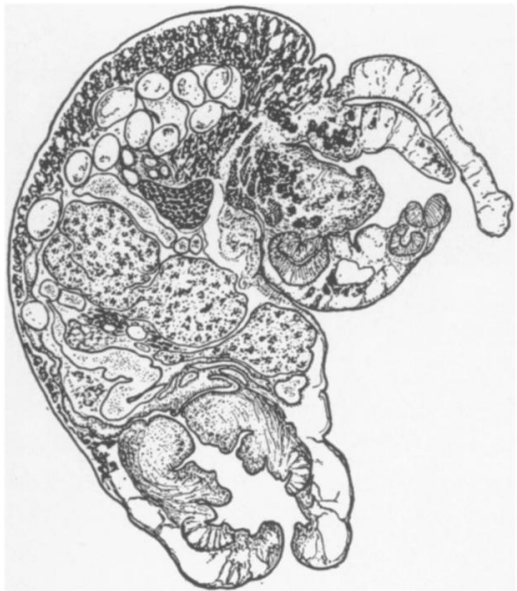
$660 \mu$ long by 405 to $510 \mu$ wide, and, after an abrupt turn, penetrates it superficially in a dorsoventral direction, following the anterior border of the organ as far as the junction with the uterus, which is introduced a little obliquely at the basal pole, after having curved in to assume the axial direction (fig. 2). The common genital canal empties into a burst copulatrix 260 to $380 \mu$ wide at the level of the muscular ring ("Ringnapf"), and 225 to $405 \mu$ deep.

Fig. 2.-Strigea macronophora n. sp., from Buteo jamaicensis borealis ( $\mathrm{Gm}$.). Sagittal section; length: $2.11 \mathrm{~mm}$.

Strigea macroconophora most nearly approaches the Australian species $S$. glandulosa Dubois (1937a, 1938), from which it is distinguished, nevertheless, by its greater size and by the great development of the genital cone and the bursa copulatrix, which, together, occupy the last third of the posterior segment (instead of the last fourth); by the larger size of the testes; by the shorter extension of the proteolytic gland; and by the geographical distribution.

Host.-Buteo jamaicensis borealis (Gmelin).

Locality.-Poynette, Wisconsin.

Habitat.-Small intestine.

Type--In the collection of the Institut de Zoologie, Universite de Neuchâtel.1

1 Whenever the quantity of material will permit, specimens will also be deposited in the Helminthological Collection of the U. S. National Museum. 


\section{Apharyngostrigea CORNu (Zeder)}

Syn. A. bilobata Olsen, 1940

This worm, studied by I. Ciurea (1927 and 1930); redescribed by one of us (G. D., 1938); then by E. E. Byrd and J. W. Ward (1943); and observed Ey I. Perez Vigueras (1944) in Cuba, was found in two ardeids, Ardea $h$. herodias L. (host number 3) from Buckeye Lake, Ohio, May 16, 1944, and in Casmerodius albus egretta (Gmelin) (host number 1), collected at Bono, Lucas County, Ohio, August 25, 1944.

We consider Apharyngostrigea bilobata Olsen, 1940, a synonym of $A$. cornu (Zeder). In fact, the only differential character would be, according to Olsen (p. 324), the bilobed form of the ovary, "being deeply cleft on the posterior margin" (p. 325). Ciurea (1927), not cited in the bibliography, had seen this organ "sensiblement ellipsoïdal, un peu excavé au-dessous," and has figured it as such (pl. I.) We recognized it as "ellipsoïdal ou réniforme" (1938) and represented it as oval (op. cit., fig. 2). In re-examining material collected by Professor Baer (from Ardea cinerea L., Geneva, November 2, 1935 ) and identified as $A$. cornu (Zeder), we have distinguished on many specimens the clearly bilobed contour of the organ, which, in a different perspective, could appear reniform, or even ellipsoidal. Vigueras (1944, fig. 1), in representing $A$. cornu, drew it in reniform; he described it as bilobed in $A$. insulae Vigueras (op. cit., p. 6 and fig. 4). It has resulted, therefore, that the distinctive character of the species described by Olsen is of no value.

Let us note that, in $A$. cornu as in A. bilobata, the proteolytic gland, ovoid in contour, is situated at the limit of the two body segments; that it is always exposed by the fact that the vitelline follicles are rather abruptly dispersed at its level, and reappear less numerous anterior to it (they are absent from the ventral wall of the anterior segment, as was remarked by Byrd and Ward, 1943 , p. 273); finally, that it is, as Olsen said (p. 323), "strongly lobulated, posterior third composed of a single large piece, anterior two-thirds composed of numerous small lobules, shape longitudinally oval." According to Ciurea (1930, p. 279), the lobules are "plus ou moins triangulaires avec les sommets concentriquees."

\section{Apatemon gRacilis (Rudolphi)}

This cosmopolitan species, common, at any rate, in the northern hemisphere (Europe, Japan, United States, Cuba), redescribed by Stunkard, Willey, and Rabinowitz (1941), was found in the intestine of a specimen of Mergus serrator L. (host number 1), collected at Buckeye Lake, Ohio, March 31, 1945. Szidat (1929a, p. 730) already cited this host, which is not mentioned in the Monagraphie des Strigeida (1938, cf. note 1, p. 104), because of the uncertainty of the determination.

The utriform anterior segment, more or less elongate and of subquadrangular profile because the dorsal edge is incurved at the level of the ventral sucker, is often withdrawn into the concavity of the second segment (state of contraction). The vitelline follicles nearly reach the posterior extremity of the body, and go up laterally to the front of the bursa copulatrix. The eggs measure 92 to 
$115 \mu$ by 61 to $80 \mu$ (average: 105 by $71 \mu$ ). In specimens fixed normally and not contracted, the testes are cordiform - having two largely rounded lobes, in most cases inequal, and especially so in the second organ-oriented anterodorsally; the axis of the first is more or less oblique, at times directed nearly crosswise to the body; that of the second is almost longitudinal (fig. 3). The anterior testis measures 270 to $280 \mu$ in dorso-ventral diameter, and 300 to 330 $\mu$ in length. The posterior testis, a little more developed, attains a dorsoventral diameter of 270 to $310 \mu$; the longitudinal dimensions are 340 to 435 $\mu$, or 300 to $360 \mu$, according to whether the measurements are of the large or the small lobe.

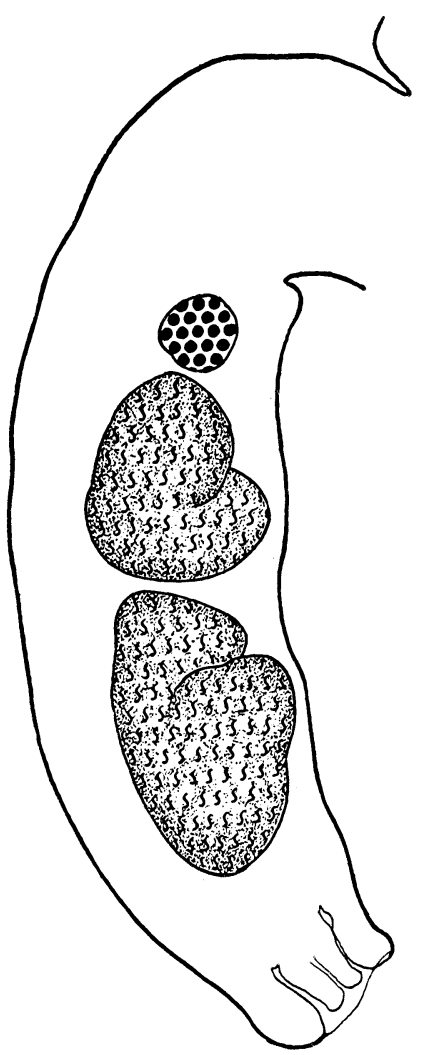

Fig. 3.-Apatemon gracilis (Rudolphi), from Mergus serrator $\mathrm{L}$. Morphology and topography of the genital glands.

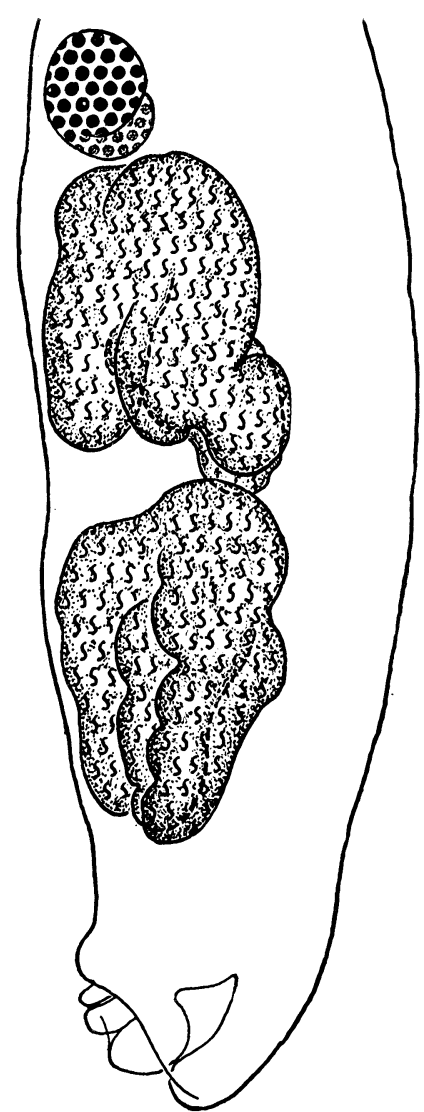

Fig. 4. - Cotylurus aquaris Guberlet), from Gavia immer (Brünn.). Morphology and topography of the genital glands.

A good representation of this strigeid, in one of its usual positions, is that given by Yamaguti (1933, fig. 2), where one can see the typical general morphology, the form and orientation of the testes, and at the same time the 


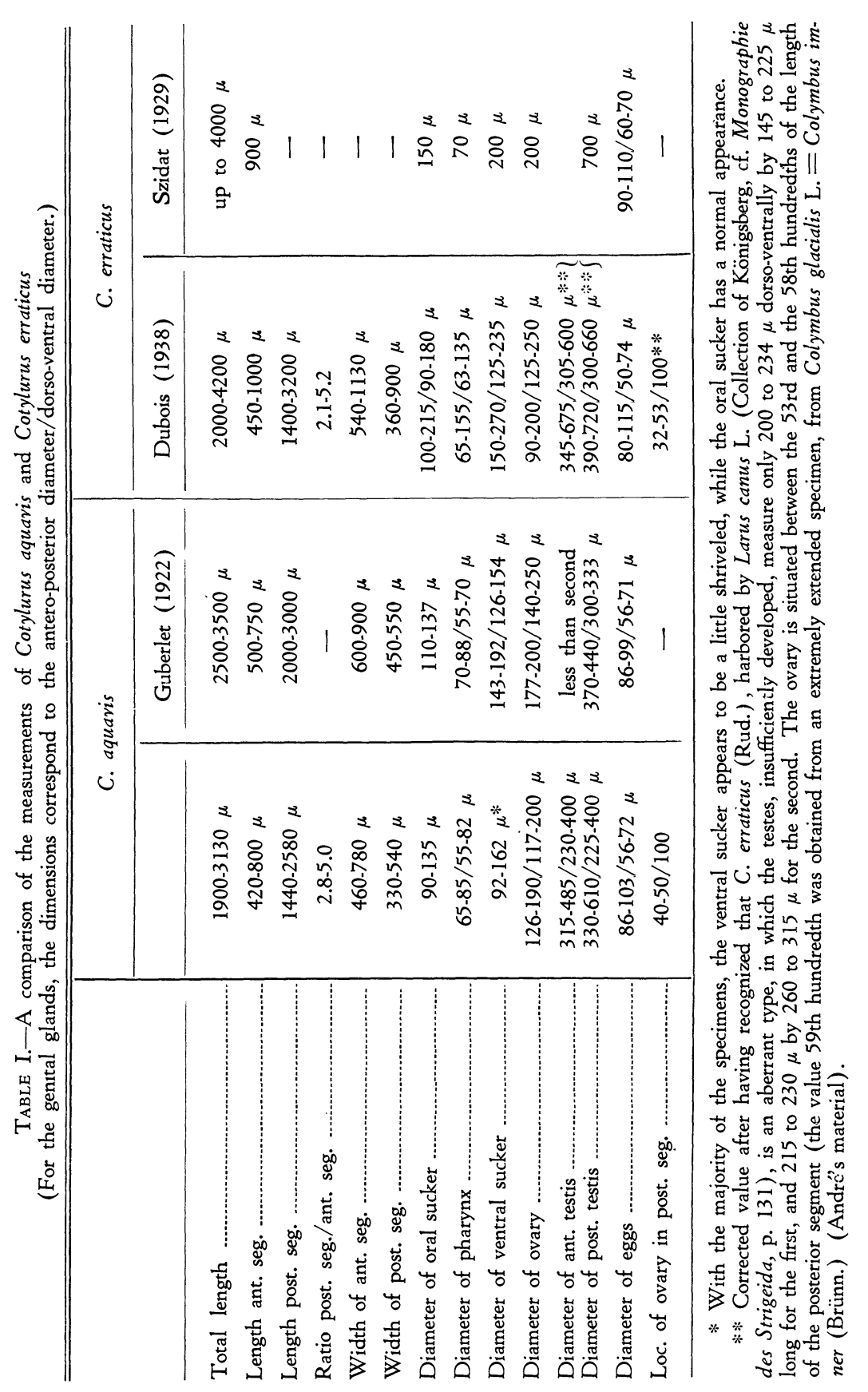


strong dorsal musculature binding the base of the anterior segment to the region of the first of these organs.

\section{Cotylurus AQuavis (Guberlet)}

We found this species in the abundant and complex material from the intestine of Gavia immer (Brünn.) (host number 1), collected on November 25, 1946, at Madison, Wisconsin. We indicate here nothing more than the results of our numerous measurements, comparing them with those obtained from a closely related European species, C. erraticus (Rudolphi), which is its counterpart.

As may be seen by the comparison of the dimensions given in the preceding table (table I), no quantitative character permits us to oppose these two species. One simply verifies that almost all the measurements made on $C$. erracticus (Rud.) surpass those of C. aquavis (Gub.) - except for the ovary. The examples of Rudolphi's species, found in Larus canus L. (Königsberg material), appear to us to be distinguished as well from the type form, adapted to Colymbi, as the American species. That is why it could be that one would conclude by considering this a variety of $C$. erraticus (Rud.), if not a synonym.

Observations on the morphology of $C$. aquavis (Gub.).-The testes, anteriorly convex, are divided into three very elongated lobes, directed backward, of which one is sometimes subdivided (giving a count of four), more or less rectilinear or sinuous, and mainly lobed; the second organ is longer than the first, but of the same width (fig. 4). The vitelline follicles extend over the entire ventral face of the second segment, reaching nearly to the posterior extremity and going laterally in front of the ovary, and also behind the testes; they usually taper into the base of the anterior segment.

The muscular process, included within the bursa copulatrix, and known by the name of "genital bulb," is a bulbiform organ only in optical section. In reality, it is a stout, semicircular pad, inserted ventrally in the base of the genital cone-which it encompasses with its free edge, obliquely truncate-protruding with it and protecting it like a viser. We have recognized the same appearance of it in C. cornutus (Rud.), C. erraticus (Rud.), and C. platycephalus (Crep.). It appears indeed to be arranged in this manner in all the species of the genus, as the following show.

\section{Cotylurus brevis n. sp.}

This worm was found in the intestine of Nyroca affinis (Eyton) (host number 11), from Grosse Ile, Michigan, March 29, 1946.

The total length is between 1.17 and $1.80 \mathrm{~mm}$. The anterior segment, 0.42 to $0.72 \mathrm{~mm}$ long and 0.33 to $0.54 \mathrm{~mm}$ wide, has the form of a deep cup, more than hemispheroidal, obliquely truncated in front, and from which scarceJy emerge the lobes of the tribocytic organ; its ventral border, nearly rectilinear and generally short $(0.33$ to $0.54 \mathrm{~mm})$, makes a very obtuse angle with the beginning of the posterior segment; on the contrary, its dorsal border, de- 
veloped by the very fact of its strong curvature in the form of a sickle, is much longer $(0.42$ to $0.90 \mathrm{~mm})$ and makes nearly a right angle with the nearly rectilinear profile of the back of the second segment. This, weakly arched and ventrally convex, has the form of a little cucumber, attenuated, and posteriorly truncated. Its dimensions are 0.75 to $1.08 \mathrm{~mm}$ in length, by 0.26 to $0.39 \mathrm{~mm}$ wide. It is excentrically fixed at the base of the anterior segment, so that the transversal constriction, which separates them, is little marked ventrally. The ratio of the lengths of the two parts of the body (posterior/anterior) varies between the following limits: 1.48 to 1.80 . This value, as one can see, is characteristic of the species.

The oral sucker, which occupies the most advanced part of the cup formed by the first segment, measures 81 to $120 \mu$ by 72 to $109 \mu$, whereas the pharynx, seen with difficulty in total preparations, reaches but 50 to $58 \mu$ by 36 to $45 \mu$ in longitudinal and transverse dimensions. The diameter of the ventral sucker is 110 to $170 \mu$ by 100 to $140 \mu$.

The ovary, small and ellipsoidal, situated at the beginning of the posterior segment, measures 91 to $96 \mu$ by 70 to $74 \mu$. The eggs, numbering about 20 in the uterus, are of the same order of size, being 92 to $103 \mu$ long by 63 to $70 \mu$ wide (average 97 by $68 \mu$ ). The vitelline glands occupy all the ventral part of the second segment, with the exception of the terminal attenuated zone, in which the bursa copulatrix remains exposed. In the largest of the specimens, a crown of follicles exists in the anterior part of the body, placed ventrally in relation to the acetabulum. This peculiarity constitutes moreover an aberrant disposition.

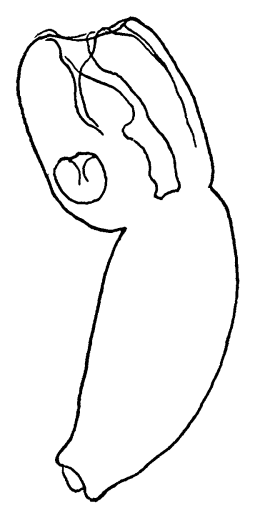

$\boldsymbol{A}$

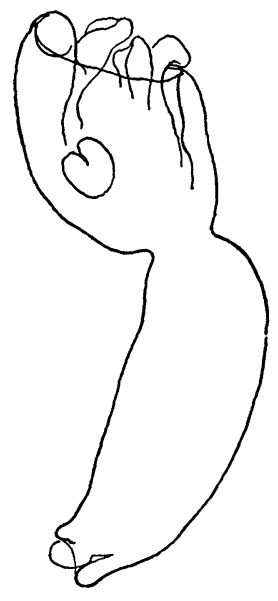

$\boldsymbol{B}$

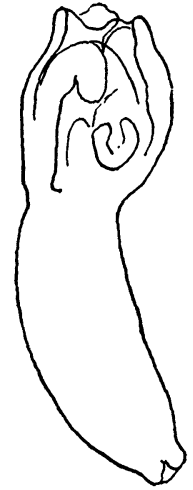

C

Fig. 5.-Outlines of Cotylurus brevis n. sp., from Nyroca affinis (Eyton). Length: A) $1.34 \mathrm{~mm}$; B) $1.80 \mathrm{~mm}$; C $1.44 \mathrm{~mm}$. 


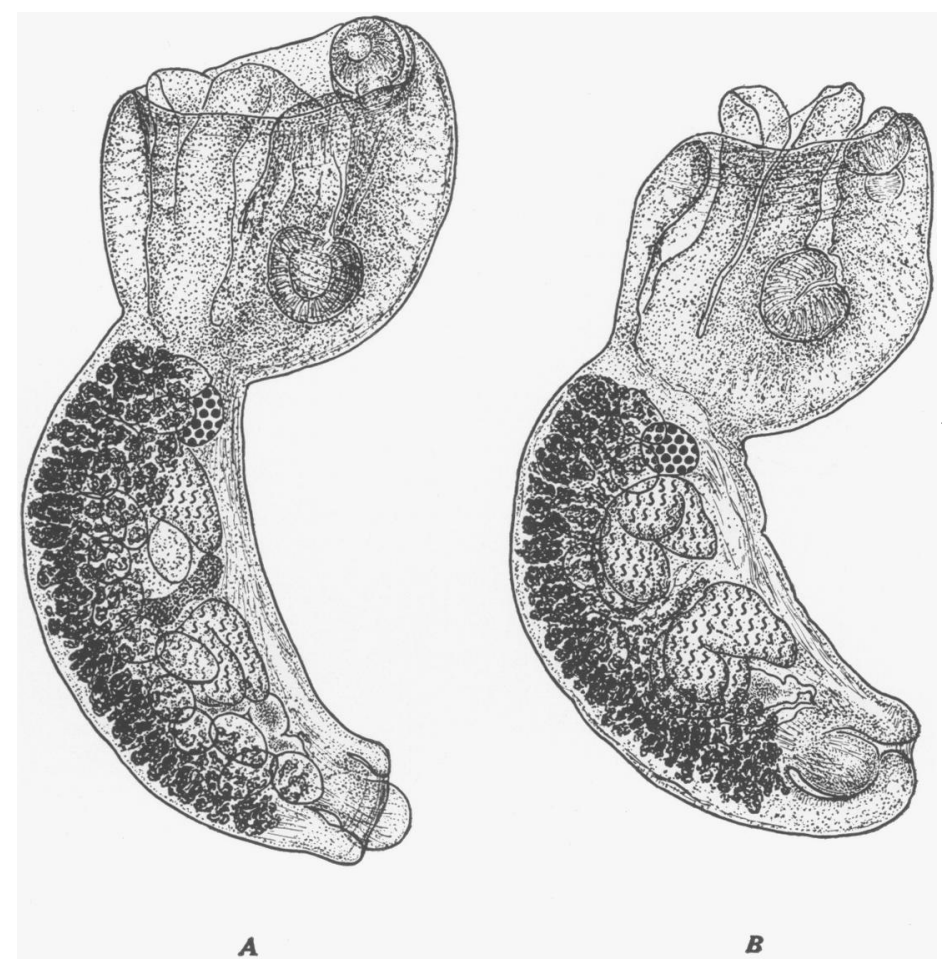

Fig. 6.-Cotylurus brevis n. sp. A) from Nyroca affinis (Eyton) (Rausch's material). Length: $1.43 \mathrm{~mm}$. B) from Somateria mollissima (L.) (Baer's material). Length: 1.49 $\mathrm{mm}$. (Form of the European type).

The testes have their lobes directed posteriorly, and the first measures 190 to $200 \mu$ long, while the second measures 180 to $215 \mu$.

Some worms, in all points similar to the specimens we are going to describe, and associated with Apatemon gracilis (Rud.), constitute material not yet utilized, collected by Professor J. G. Baer at Neuchâtel (Switzerland), in November, 1941, from the intestine of Somateria mollissima (L.). The characteristics are: the ratio of the length of the posterior segment to that of the anterior segment has the value included between 1.53 and 1.81; the ovary is situated between the 8th and the 17th hundredths of the length of the posterior segment, and is small, 84 to $115 \mu$ by 75 to $100 \mu$. The testes are divided into three lobes, largely rounded, and directed backward.

In this regard and for the general morphology, these worms resemble $C$. cornutus (Rud.) enough that we have seen the necessity for examining the diverse materials which served for the description of the latter (cf. Monographie des Strigeida, list of hosts, pp. 126-127). A comparative table of the 
measurements and their ratios, for each of the lots examined, has convinced us of the existence of two distinct species, easily enough opposable, but nevertheless confused until now. The one is represented by the specimens from Gallinago gallinago (L.) Berlin, no. 1378, Rudolphi Collection); from Vanellus vanellus (L.) (Upsala); from Nyroca ferina (L.) (Bucarest; fig. 64 of the Monograph); and of Columba livia Briss. (Sprehn's material). The other is constituted by the examples from So-

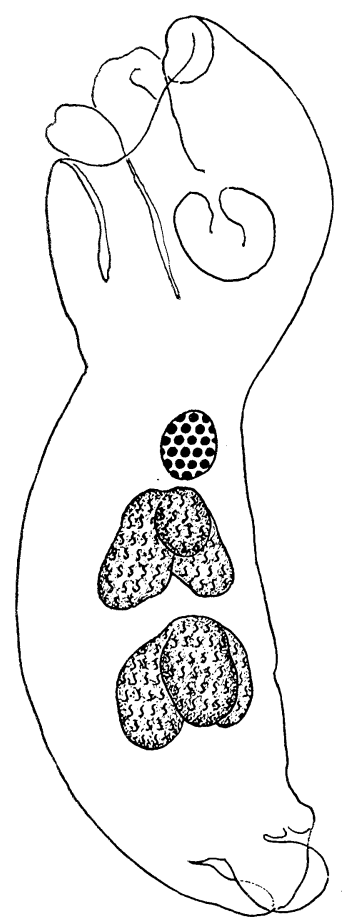

Fig. 7. - Cotylura brevis n. sp., from Somateria mollissima (L.) (Baer's material). Morphology and topography of the genital glands; length: $1.56 \mathrm{~mm}$. materia mollissima (L.) (Baer's material), which has been mentioned above, to which are added those from the same host collected by Professor André; those from Nyroca fuligula (L.) (Fuhrmann's material); and those from Nyroca marila (L.) (Andre's material). The first is indeed the species found by Rudolphi at Greifswald, in the intestine of Charadrius apricarius L. = Charadrius pluvialis L., and described in 1809. It possesses a "semiglobular" anterior segment, horizontally truncated, and measuring "a peine moins qu'ne ligne" (according to Dujardin: $2.2 \mathrm{~mm}$ ). The second is Cotylurus brevis n. sp., of which the anterior segment, a little longer than wide, is obliquely truncated above the equator of the spheroid to which it can be compared; the total length is less, because the posterior segment is much shorter than it is in Rudolphi's species.

It is to this second form that can be attributed the worm described by J. Timon-David (1943), under the name of Cotylurus cornutus (Rud.), and obtained experimentally from the Chinese teal, Aix galericulata L., from the tetracotyles harbored by Limnaea palustris (O. F. Müller). The form of the body, the dimensions of the posterior segment (0.76 to 1.0 $\mathrm{mm}$ ) and of the ovary (95 to $110 \mu)$, and in the same way the value of the ratio "posterior segment to anterior segment" (1.27 to 1.67) permit this attribution.

The following table (table II) introduces the distinctive characters.

The two species which we have just compared are defined as follows: Cotylurus cornutus (Rud.) Anterior segment hemispherical, cupuliform, wider than long-from which freely emerge the lobes of the tribocytic organ-delimited by a strong, transverse constriction, and excentrically attached to the posterior segment, which is about $2 \mathrm{I} / 2$ to $4 \mathrm{I} / 2$ times longer, a little arched, and 
in the form of an elongate kidney. Vitelline glands strongly developed; follicles strictly limited to the posterior segment, at the beginning of which they have at first a strong density, and occupy the ventral half, up to a little distance from the posterior extremity to the extent that the bursa copulatrix is generally visible. Ovary spherical, of middle size, situated between the 16th and the 34th hundredths of the length of the posterior segment. Testes anteriorly convex, divided into 3 largely rounded lobes, and directed backward.

Hosts.-Charadrius apricarius L. (original material); Gallinago gallinago (L.) (Rudolphi Collection, no. 1378); Numenius arquata (L.) (Skrjabin, 19282'; Szidat, 1929a, fig. 26, b); Scolopax rusticola L. (probably) (Rudolphi

2 Total length: 1.2 to $3.0 \mathrm{~mm}$.

TABLE II.-Comparison of the dimensions of Cotylurus cornutus (Rud.) with those of Cotylurus brevis n. sp.

\begin{tabular}{|c|c|c|c|}
\hline \multirow{3}{*}{$\begin{array}{l}\text { Geographical distribution } \\
\text { Material collected by or at: .............................. }\end{array}$} & \multirow{3}{*}{$\begin{array}{c}\text { C. cornutus (Rud.) } \\
\text { Europe } \\
\text { Rudolphi, Sprehn } \\
\text { (Upsala, Bucarest) }\end{array}$} & \multicolumn{2}{|c|}{ C. brevis n. sp. } \\
\hline & & Europe & North America \\
\hline & & $\begin{array}{l}\text { Baer, André } \\
\text { Fuhrmann }\end{array}$ & Rausch \\
\hline Total length & $1250-2200 \mu$ & $1000-1770 \mu$ & $1170-1800 \mu$ \\
\hline Length of anterior segment ............. & $300-600 \mu$ & $390-720 \mu$ & $420-720 \mu$ \\
\hline Length of posterior segment ............. & $900-1820 \mu$ & $650-1110 \mu$ & $750-1080 \mu$ \\
\hline Ratio of post. segment/ant. segment & 2.43.4.40 & 1.25.1.94 & $1.48-1.80$ \\
\hline Width of anterior segment .............. & $340-800 \mu$ & $340-690 \mu$ & $330-540 \mu$ \\
\hline Width of posterior segment ................. & $380-640 \mu$ & $300-660 \mu$ & $260-390 \mu$ \\
\hline Diameter of oral sucker ..................... & $65-130 \mu$ & $85-108 / 80-108 \mu$ & $81-120 / 72-103 \mu$ \\
\hline Diameter or pharynx & $45.110 \mu$ & indistinct & $50-58 / 36-45 \mu$ \\
\hline Diameter of ventral sucker ................ & $100-200 \mu$ & $110-180 / 96-170 \mu$ & $110-170 / 100-140 \mu$ \\
\hline Diameter of ovary & $144-216 / 135-190 \mu$ & $75-150 / 65-120 \mu$ & $91-9.6 / 70-74 \mu$ \\
\hline Diameter of anterior testis .................. & $225-360 / 210-450 \mu$ & $135-295 / 180-320 \mu$ & $190-200 / \quad ? \mu$ \\
\hline Diameter of posterior testis .............. & $270-450 / 250-450 \mu$ & $160-340 / 180-315 \mu$ & $180-215 / ?$ \\
\hline Diameter of eggs & $81-110 / 51-73 \mu$ & $91-110 / 50-70 \mu$ & $92-103 / 63-70 \mu$ \\
\hline Position of ovary in post. segment .. & $16-34 / 100$ & $8-17 / 100$ & $11-22 / 100$ \\
\hline & $a v .24 / 100$ & av. $13 / 100$ & \\
\hline
\end{tabular}

(For the testes, the dimensions correspond to the antero-posterior diamet er/dorso-ventral diameter.) 
Collection, no. 1385); Vanellus vanellus (L.) (Upsala material) ${ }^{3}$ Nyroca ferina (L.) (Bucarest material); Columba livia Briss. (Sprehn's material, Bittner, 1927).

Habitat.-Intestine.

Distribution.-Europe and Transbaikal.

Cotylurus brevis n. sp.-Anterior segment subglobular, generally longer than wide, in the form of a deep, spheroidal dome, obliquely truncated in front and narrowed at the mouth-from which hardly emerge the lobes of the tribocytic organ-curved at the dorsal border as a sickle, and at the extremity of which the oral sucker juts out; posterior segment $1 \mathrm{r} / 4$ to 2 times longer, a little arched in the form of a kidney or a little cucumber, delimited by a transversal constriction-not distinct ventrally-and attached excentrically to the preceding. Vitelline glands much developed; follicles limited to the posterior segment, at the beginning of which they have at first a greater density, and of which they occupy the ventral half to within a short distance of the posterior extremity, so that the bursa copulatrix is generally visible. Ovary of small size, ellipsoidal, situated between the 8th and the 22nd hundredths of the length of the posterior segment. Testes anteriorly convex, divided into three lobes, largely rounded and directed backwards (fig. 7).

Hosts.-Somateria mollissima (L.) (Baer's and André's material); Nyroca fuligula (L.) (Fuhrmann's material); Nyroca marila (L.) André's material); Nyroca affinis (Eyton) (Rausch's material); Aix galericulata L. (TimonDavid, 1943).

Habitat.-Intestine.

Distribution.-Europe and North America.

Types and cotypes.-from Somateria mollissima (L.) (Baer's material, of November, 1941), deposited in the collection of the Institut de Zoologie, Univetsité de Neuchâtel.

Remark I. It is confirmed that two species have been confused up to now under the name of "Cotylurus cornutus (Rud.)." One could expect such a duplication for several reasons: (1) variable position of the ovary; form of the globular to hemispherical anterior segment, which is now wider than long, now longer than wide; distant limits of the value of the ratio "posterior segment to anterior segment"; (2) differences observed between the two related cercariae: Cercaria A. Szidat, ${ }^{4}$ considered to be the larva of Cotylurus cornutus (Rud.), and Cercaria helvetica XXXIV Dubois, 1934; (3) facultative

3 Nazmi (1935) cited Oedicnemus crepitans Temm. as host of Cotylurus cornutus, but, in absence of data on the parasite, one can not be sure that it is Rudolphi's species.

4 Probably identical with Cercaria sanjuanensis Miller, 1927. 
or conditional evolution of the metacercariae either in the hermaphrodite gland of molluscs, or in the circulatory system of leeches; (4) more or less free adaptation of the adults to two orders of birds: the Charadrii and the Anseres. 5

Remark II. The two species of Cotylurus for which we have just established the diagnoses have not only been taken one for the other, but have been often confused with Apatemon gracilis (Rud.), which is of about the same size, and which also belongs to the sub-subfamily Cotylurini Dubois. Certainly, aside from their different morphology and the difference in the copulatory apparatus (cf. Szidat, 1929b, p. 145, fig. 5 and 6), they are anatomically distinguished by their male sex glands: in A. gracilis, the cordiform testes orient their two lobes aritero-dorsally, whereas in C. cornutus and C. brevis-as in other respects with C. aquavis (Guberlet) and its counterpart, C. erraticus (Rudolphi) (Europe) - - -the two organs, anteriorly convex, are divided into three lobes directed backward.

Remark III. Cotylurus flabelliformis (Faust) is distinguished from the two species which we have just compared by the much smaller size $(0.56$ to $0.85 \mathrm{~mm}$ ) and by the fact that the oral sucker is nearly equal to the acetabulum.

\section{Cotylurus medius n. sp.}

The description of this species is based on the examination of two lots of material from the small intestine of Sterna hirundo L. (host numbers 1 and 2), collected on August 25, 1944, at Bono, Ohio.

The birds from which these trematodes were taken were still in the down stage, and were taken directly from the nest. It is of interest to note that we have not taken this strigeid from adult terns, of which 23 have been examined. All the birds examined were taken from the same general region (central part of Lake Erie, in both Ohio and Michigan).

The total length "of this worm varies between 2.10 and $3.75 \mathrm{~mm}$. From point of view of size, this form is intermediate between the smallest, as $C$. flabelliformis (Faust), and the largest, such as C. communis (Hughes). According to its dimensions and occurrence, it appears to be very similar to $C$. pileatus (Rud.), found in Europe in gulls and terns.

The anterior segment, largely cupuliform, depressed, and compact, more rarely sub-globular, measures 0.50 to $0.84 \mathrm{~mm}$ in length, by 1.0 to $1.41 \mathrm{~mm}$ transversely. It is excentrically fastened to the thick posterior segment, more

5 Mathias (1925, p. 32) reported having readily obtained the one of these parasites by experimental infection of tame and wild ducks, but to have tried vainly to obtain it in the lapwing (nutritional conditions?). 
or less arched, sub-reniform to sacciform-rounded or truncated at the extremity-distinctly separated from the preceding by a strong, transverse constriction; the dimensions are 1.60 to $3.0 \mathrm{~mm}$ in length, by 0.84 to $1.44 \mathrm{~mm}$ in width. The ratio of the lengths of the second segment to the first is 2.80 to 4.10.

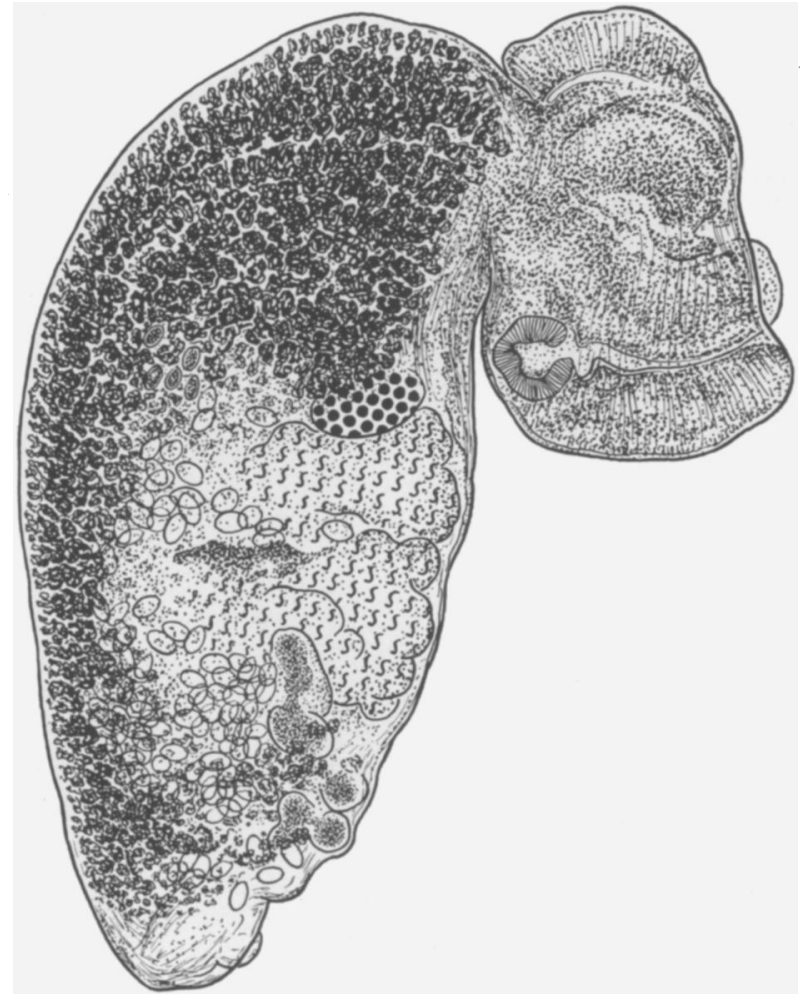

Fig. 8.-Cotylurus medius n. sp., from Sterna hirundo L. Type specimen; length: $3.75 \mathrm{~mm}$.

The diameter of the submarginal oral sucker-of which the center is situated between the 16th and 19th hundredths of the length of the anterior seg. ment, and of which the frontal border is 20 to $55 \mu$ distant from the margin of this-is from 140 to $163 \mu$; the dimensions of the ventral sucker reach 180 to $270 \mu$; those of the pharynx from 90 to $155 \mu$ by 80 to $125 \mu$.

The ovary, which one sees between the 36th and 50th hundredths of the posterior segment, measures 180 by $250 \mu$ in diameter. It is placed dorsally, immediately in front of the massive testes, which are roughly multilobed, and of which the dimensions (longitudinal/dorso-ventral) reach, for the first, 540 by $720 \mu$, and for the second, 780 by $690 \mu$. The uterus develops numerous 
convolutions filled with eggs over all the length of the segment; the eggs measure 96 to $126 \mu$ by 53 to $78 \mu$ (average 105 by $63 \mu$ ). The vitelline follicles are concentrated anteriorly, ventrally, and posteriorly in relation to the genital glands, and extend almost to the extremity of the body, completely masking the bursa copulatrix, of which the pore is dorsal and subterminal, only if it is retracted.

Cotylurus medius is, in North America, the counterpart of C. pileatus (Rud.), of Eurasia. It is perhaps distinguished adequately by the distinctly greater dimensions of the eggs (those of $C$. pileatus measured by one of us (G. D.) : 82 to $99 \mu$ by 50 to $66 \mu$; according to Szidat: 90 by $50 \mu$ ); by the widening of the anterior segment (which has a diameter of but 0.81 to $1.02 \mathrm{~mm}$ in the Eurasiatic species); and by the greater development of the pharynx ( 80 to $100 \mu$ in C. pileatus), when the oral suckers of the two species are subequal.

Host.-Sterna hirundo L.

Habitat.-Intestine.

Distribution.-Bono, Lucas County, Ohio.

Types and Cotypes.--deposited in the collection of the Institut de Zoolo. gie, Université de Neuchâtel.

\section{Family Diplostomatidae Poirier \\ Diplostomum gavium (Guberlet)}

A dozen specimens of this diplostome were found in the material from Gavia immer (Brünn.) (host number 1); these serve us as a basis for the redescription of $C$. aquavis (Gub.). Here are the results of our measurements:

Total length 1050 to $1740 \mu$

Length of anterior segment . 690 to $1140 \mu$ Length of posterior segment 330 to $660 \mu$

W'idth of anterior segment .................................................................... 325 to $480 \mu$

Width of posterior segment ................................................................ 250 to $350 \mu$

Width at level of bursa copulatrix ....................................................... 185 to $230 \mu$

Ratio of lengths of posterior segment to anterior segment 0.45 to 0.65

\begin{tabular}{|c|c|c|}
\hline Diameters of: & antero-posterior & transverse \\
\hline oral sucker. & 72 to $98 \mu$ & 80 to $108 \mu$ \\
\hline pharynx ........... & 60 to $72 \mu$ & 48 to $57 \mu$ \\
\hline 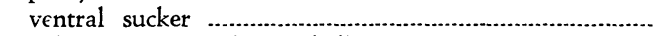 & 70 to $100 \mu$ & 80 to 115 \\
\hline tribocytic organ (expanded) ... & 180 to $315 \mu$ & 210 to 395 \\
\hline ovary & 110 to $115 \mu$ & 117 \\
\hline testis & 100 to $200 \mu$ & 260 to 330 \\
\hline second testis & 120 to $195 \mu$ & 240 to $280 \mu$ \\
\hline eggs ….............. & 85 to $92 \mu$ & 54 to 66 \\
\hline
\end{tabular}

Distance from posterior edge of ventral sucker to anterior edge of tribocytic organ (in expansion) 
Diameter of genital cone

Position in the anterior segment of:

posterior edge of pseudo-suckers

Observations on the morphology of D. gavium (Gub.).-The bisegmentation of the body is slightly demarcated. The limit of the two parts is seen, in specimens viewed from the side, as a rather abrupt flexion, visible chiefly on the ventral profile, where it makes an obtuse angle. The anterior segment is characterized by the existence of very large pseudo-suckers. The extremity of the conical posterior segment is dorsally more or less distinctly bent in the attenuated region which contains the bursa copulatrix, and which is delimited by a very slight constriction.

In the specimens of this lot, the oral sucker is sometimes a little larger than the ventral sucker, sometimes it is the opposite; one can say that the two organs are subequal in diameter (Guberlet, 1922, p. 9, indicated 60 by $80 \mu$ for the first, and $70 \mu$ for the second). The tribocytic organ, everywhere expanded, is wider than long (the dimensions given by Guberlet correspond to a state of contraction: 135 to $175 \mu$ in length, by $100 \mu$ in width, cf. pl. V, fig. 11).

In the anterior segment the vitelline follicles extend nearly to the middistance between the two suckers; they are rather abundant at the level of the tribocytic organ, which they overgrow. In the posterior segment their field is restricted to the level of the first testis, to constitute a narrow median and ventral strip, which terminates as two small, lateral curls, behind the second testis; that is to say, anterior to the bursa copulatrix. This always remains exposed, therefore; it screens a genital cone and opens by a large, subterminal, dorsal pore.

In the specimens seen face-on, and on account of the flexion of the long axis of the body, the laterally situated ovary projects into the basal region of the anterior segment, encroaching sometimes into the zone of the tribocytic organ. The testes, bilobed or in the form of a dumb-bell, occupy all the width of the first half of the posterior segment: the first of these organs is more developed, in the transverse direction, than the second.

\section{Diplostomum repandum n. sp.}

These trematodes were taken from the intestine of Sterna hirundo (L.) (host number 1), collected August 25, 1944, at Bono, Ohio. They are characterized by their strong flexure as much as by the great development of the tribocytic organ.

The total length of the body-which is divided by a strong transverse constriction-varies from 1.20 to $2.34 \mathrm{~mm}$. The anterior foliform segment, of 
oval contour, is depressed in the contracted state, taking the appearance of a cup of which the turned up borders screen a fungoid tribocytic organ. Its dimensions are 0.51 to $1.02 \mathrm{~mm}$ in length, by $0.72 \mathrm{~mm}$ in maximum width (measured in the second half in two en face specimens). The posterior segment, ovoid to sacciform, is sub-equal to the preceding, to the dorsal surface of which it is attached, and becomes attenuated, making with it nearly a right angle-which explains that the greater part of the specimens, mounted as total

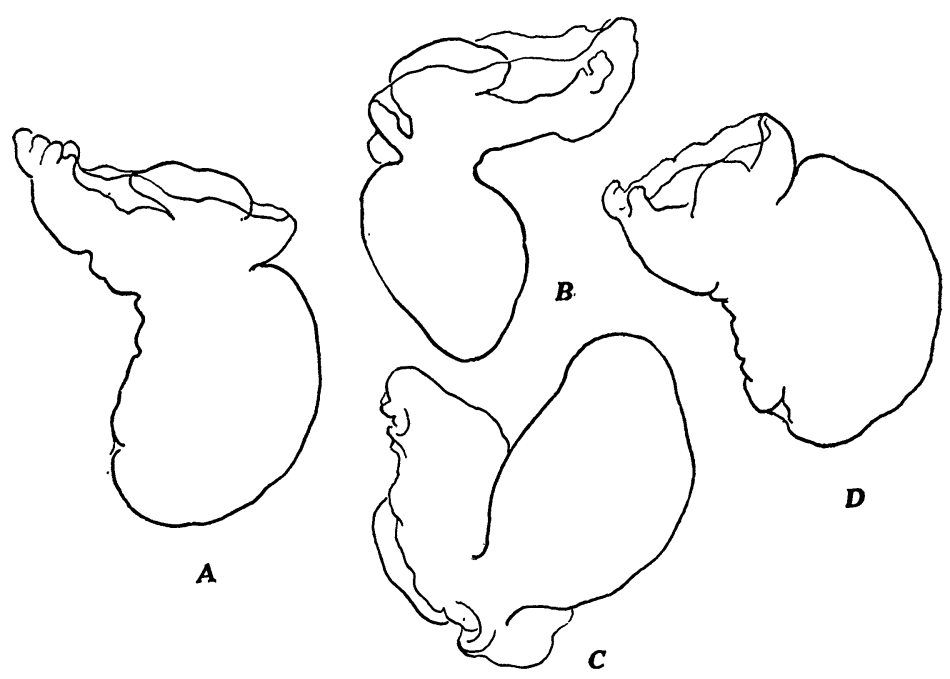

Fig. 9.- Outlines of Diplostomum repandum n. sp., from Sterna hirundo L. Length

A) $1.38 \mathrm{~mm}$; B) $1.29 \mathrm{~mm}$; C) $1.70 \mathrm{~mm}$; D) $1.20 \mathrm{~mm}$ (strongly contracted).

preparations, are placed on the side and appear strongly bent. Its length varies from 0.58 to $1.38 \mathrm{~mm}$; its width from 0.57 to $0.63 \mathrm{~mm}$; and its dorsoventral diameter from 0.42 to $0.63 \mathrm{~mm}$. The ratio of the length of the posterior segment to that of the anterior segment has a value between 0.76 and 1.57 , with an average of 1.12 .

The oral sucker, globular in shape, measures 86 to $115 \mu$ in antero-posterior diameter, by 86 to $120 \mu$ in transverse diameter. It is flanked by two semilunar pseudo-suckers, situated at the level of the pharynx: This is strongly muscular, largely ellipsoidal, and nearly spherical when it is contracted; its length is from 79 to $96 \mu$, and its transverse diameter from 65 to $95 \mu$. The bifurcated intestine has no oesophagus. A single specimen presented a faceon view of the ventral sucker; this measured 115 by $137 \mu$. On the other examples the acetabulum, which is situated between the 44th and 50th hundredths of the length of the anterior segment, is covered in part or totally by the tribocytic organ; this, in a state of expansion on all specimens, measures 320 to $480 \mu$ in length by 460 to $490 \mu$ in width; its anterior border and its center are found respectively between the 35 th to 50 th hundredths and the 
60 th to 70 th hundredths of the length of the first segment. This last dimension, in relation to the longitudinal diameter of the tribocytic organ, gives a value between 1.56 and 2.60 (average: 2.09). The sections reveal the great development of the proteolytic gland.

The testes distend the posterior segment. The second, larger than the first, occupies all the width and measures 500 to $520 \mu$ in the transverse dimension, and 225 to $330 \mu$ longitudinally on one or the other of its sub-equal halves. Its posterior margin is situated between the 70th and the 79th hundredths of the length of the segment. The first testis, asymmetrical, or, in all cases, more developed on the side where the larger half of the second is found, attains 160 to $250 \mu$ in the antero-posterior dimensions.

The ellipsoidal ovary, placed between the 18th and 26th hundredths of the length of the segment, measures 117 to $135 \mu$ by 145 to $160 \mu$. The vitelline follicles accumulate in the restricted space which occurs in front of the genital glands, becoming reduced to a ventral, median ribbon, allowing the exposure 320 to $480 \mu$ in length by 460 to $490 \mu$ in width; its anterior border and its center are found respectively between the 35th to 50th hundredths and the 60th to 70th hundredths of the length of the first segment. This last dimension, in relation to the longitudinal diameter of the tribocytic organ, gives a value of the lateral parts of the testes, and abutting against the two rather compact, terminal accumulations behind these. In the anterior segment, one finds them widely distributed, invading the tribocytic organ and having their limit between the 30th and 41st hundredth of this part of the body. The numerous eggs measure 90 to $108 \mu$ by 60 to $72 \mu$.

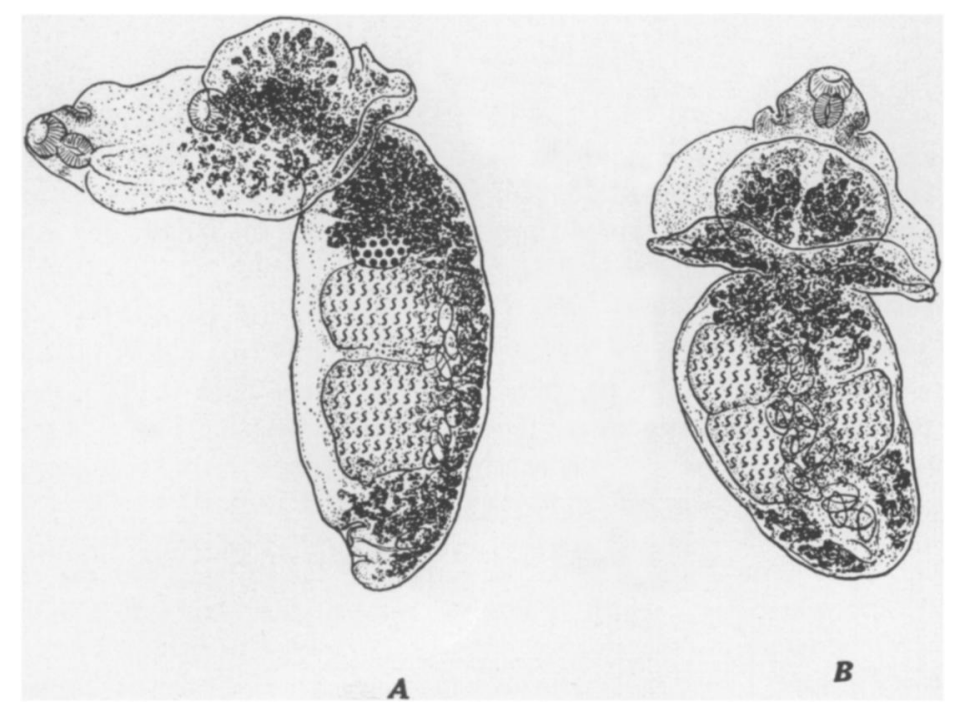

Fig. 10.-Diplostomum repandum n. sp., from Sterna hirundo L. A) Lateral view; length: $1.89 \mathrm{~mm}$. B) Ventral view; length: $1.47 \mathrm{~mm}$. 
The butsa copulatrix, of which the pore is dorsal and subterminal, is not deep. The common genital canal, which prolongs the incurved uterus, empties here, sometimes carried outward by an eminence more or less distinct, and resembling a genital cone.

This species, characterized as we have indicated above, is distinctly differentiated from those found in North American larids: D. flexicaudum (Cort and Brooks), D. indistinctum (Guberlet), and D. huronense (La Rue). It is not to be confused with the diplostomes of the stercorariids ( $D$. baeri Dubois, 1937a and 1938), found in Switzerland, nor with D. commutatum (Diesing) of Europe, a parasite of terns, with which it has the most analogy. The last, however, surpasses it ( 2.40 to $3.18 \mathrm{~mm}$ ), having a long ovoid, or fusiform to claviform, posterior segment, which at the same time is much wider (ratio of lengths of "posterior segment to anterior segment" $=1.58$ to 1.97 ); the longitudinal axis of its pharynx ( 84 to $91 \mu$ ) exceeds that of the oral sucker ( 75 to $82 \mu$ ); the genital glands are much larger; and the body does not show the flexure characteristic of $D$. repandum.

The description of Diplostomum micradenum (Cort and Brackett), given by Olivier (1940), and figures 11 to 13 which illustrate it, do not reveal adequately the features of the species to permit a rigorous comparative examination. That is why we place in addendum a figure of this species, executed after one of the specimens of the original material (U. S. N. M., Helm. Coll., no. 36701). D. micradenum is of much smaller size (1.04 to $1.35 \mathrm{~mm}$ ) than $D$. repandum; the division of its unbent body into two segments is marked only by a very weak transverse constriction. The length of the first asymmetrically developed testis (150 to $220 \mu$ ) surpasses that of the second (130 to $190 \mu)$.

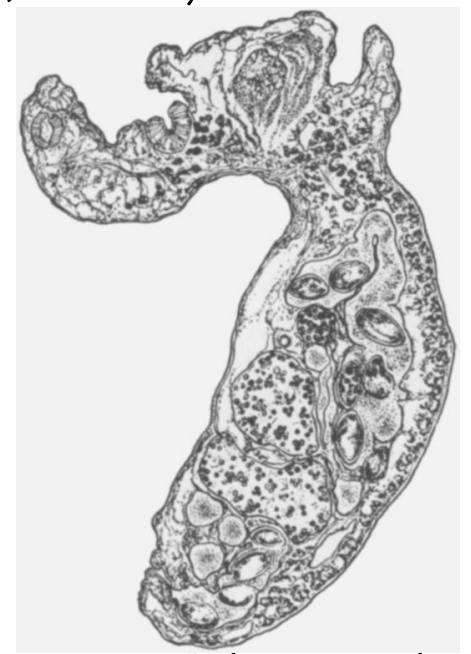

Fig. 11.-Diplostomum repandum n. sp., from Sterna hirundo L. Sagittal section.

Host.-(of D. repandum n. sp.) Sterna hirundo (L.).

Habitat.-Intestine.

Distribution.-Bono, Lucas County, Ohio.

Type.-Deposited in the collection of the Institut de Zoologie, Université de Neuchâtel.

\section{Mesoophorodiplostomum PRICEI (Krull)}

Many specimens of this species belonging to a genus well characterized by the intertesticular ovary and the evaginable bursa copulatrix, were found among 
specimens of diplostomes from gulls, 6 collected from the intestine of Larus argentatus Pont. (host number 13), captured at Madison, Wisconsin, November 13, 1946.

Some have no eggs, while others contain eggs (1 to 5). Being fixed in a state of extension, and measuring 1.90 to $2.28 \mathrm{~mm}$ in total length, by 0.37 in maximum width, they appear not to have attained their full deveolpment. Their slenderness contrasts with the more massive form of the original specimens, experimentally obtained by Krull in Larus novae-hollandiae Stephens. Nevertheless, it is of the same species, as the following measurements and their ratios show (cf. Monographie des Strigeida, pp. 209-210, and fig. 131):

6 These will be ultimately determined.

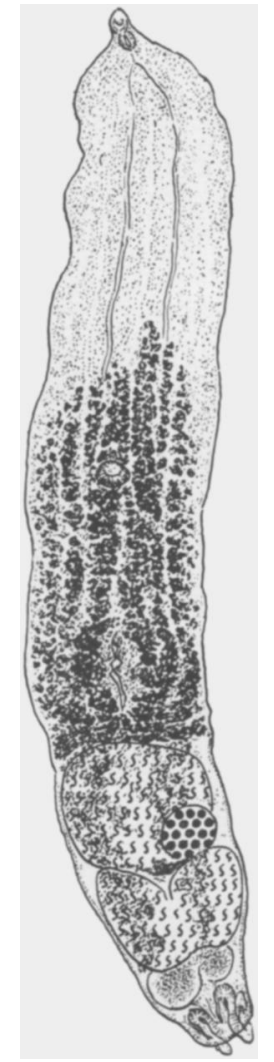

Fig. 12.-Mesoophorodiplostomum pricei (Krull), from Larus argentatus Pont. Length: $2.07 \mathrm{~mm}$.

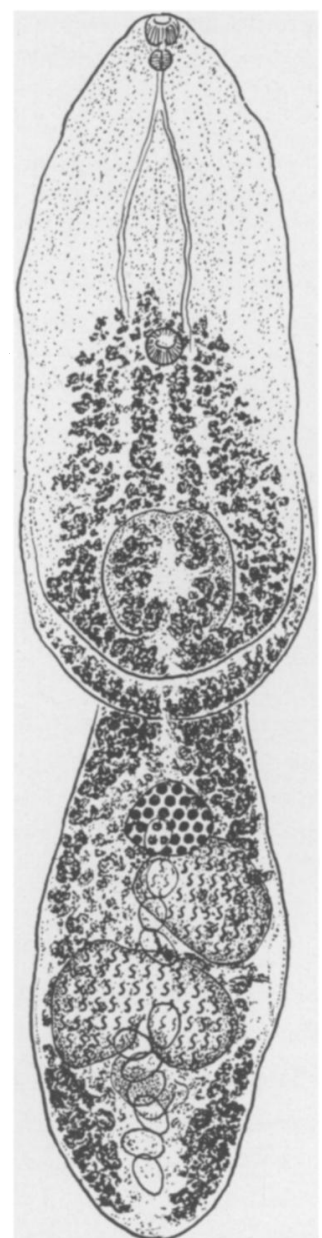

Fig. 13. - Neodiplostomum buteonis $\mathrm{n}$. sp., from Buteo jamaicensis borealis ( $\mathrm{Gm}$.). Type specimen; length: $2.95 \mathrm{~mm}$. 
Anterior segment 1.23 to $1.44 \mathrm{~mm}$ by 0.36 to $0.37 \mathrm{~mm}$. Posterior segment 0.63 to $0.75 \mathrm{~mm}$ by 0.30 to $0.33 \mathrm{~mm}$. Ratio of the length of the posterior segment to that of the anterior segment .... 0.43 to 0.56 .

Diameters of:

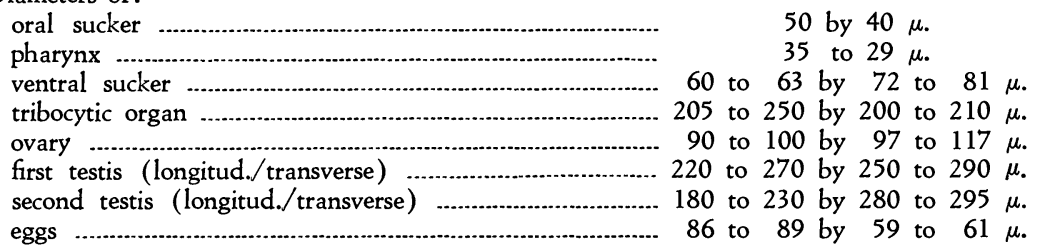

Location in the anterior segment of: most advanced vitelline follicles .................................................................. 36 to 42/100. ventral sucker .................................................................................................. 59 to 64/100. anterior border of tribocytic organ ............................................................. 80 to 83/100.

Location in the posterior segment of: anterior margin of first testis posterior margin of second testis

Besides the situation of the ovary between the testes and the extrusability of the bursa copulatrix, the characters of the species are:

(1) slightly demarcated bisegmentation of the body;

(2) the slight excavation of the foliform anterior segment, which is pointed at the cephalic extremity, occupied by a small oral sucker;

(3) the ovoid to subconical form of the posterior segment, which is shorter than the preceding;

(4) the extension of the testes over all the wicth of the first $2 / 3$ to the first $4 / 5$ of the segment-the first, of which the frontal edge is exactly at the limit of the two parts of the body, being ellipsoidal and transversely elongated; the second, reniform to sub-cordiform, with an anterior concavity and curved in a horse-shoe shape, is larger than the preceding;

(5) the limits of the vitelline follicles are in front of the ventral sucker, and at the level of the posterior border of the second testis.

\section{Neodiplostomum buteonis $\mathrm{n}$. sp.}

This worm, found with Strigea falconis Szidat, was collected from the intestine of Buteo jamaicensis borealis (Gmelin) (host number 1), shot on October 29, 1944, at Greenville, Ohio.

The body, distinctly bisegmented, measures from 2.64 to $2.95 \mathrm{~mm}$ in total length. The elongate elliptical to lanceolate anterior segment has borders curved only backward, where it is wider; its dimensions are: 1.47 to $1.66 \mathrm{~mm}$ by 0.66 to $0.69 \mathrm{~mm}$. The posterior segment, in form of an elongate ellipsoid, is always shorter than the preceding. The measurements of the main axis vary between 1.17 and $1.30 \mathrm{~mm}$; its transverse diameter reaches the maximum 
at the level of the testes, being $0.60 \mathrm{~mm}$. The ratio of the length of the posterior segment to that of the anterior segment is between 0.74 and 0.81 .

The oral sucker measures 62 to $72 \mu$ long by 67 to $81 \mu$ wide. The ventral sucker, larger and circular, has a diameter of 80 to $85 \mu$; it is situated on an average at 47 hundredths of the length of the anterior segment. Its posterior border is at a distance of 225 to $315 \mu$ from the anterior edge of the tribocytic organ. This, approximately circular, measures 315 to $335 \mu$ in length, and 290 to $315 \mu$ in width. Thus its diameter is equal to the distance which separates it from the ventral sucker. Its front is situated between the 65 th and the 71 st hundredths of the length of the anterior segment; its center between the 75th and the 80th hundredths. The ratio of the length of the anterior segment to that of the tribocytic organ varies from 4.66 to 5.24 .

Preceded by a short prepharynx ( 0 to $12 \mu$ ), the spherical pharynx measures 54 to $60 \mu$ in length, by 55 to $62 \mu$ in width. The oesophagus reaches a length of 60 to $90 \mu$. The ceca are narrow (about 10 to $15 \mu$ ) in their visible section.

The ovary, situated between the 16th and 21st hundredths of the length of the posterior segment (average of 1/5), measures 160 to $165 \mu$ in longitudinal diameter, and 190 to $210 \mu$ in transverse diameter. In the anterior segment, the vitelline glands have their limit at the level of the front of the ventral sucker, or slightly ahead of it (that is, between the 40th and the 44th hundredths of the length of the segment). From thence, and toward the rear, the follicles, separated in longitudinal bands, widen their rows a little to reach the margins of this part of the body, and show its narrow fold by their greater density. In the posterior segment, they are prolonged in the form of two lateral clusters, interrupted in the zone of the testes, and reappearing wider, but a little less dense, beyond these organs, to terminate in the rounded extremity of the segment. The eggs, few in number, measure 92 to $101 \mu$ by 59 to $75 \mu$ (average: 97.5 by $69.5 \mu$ ). The genital pore is dorsal and subterminal; the anterior border of the bursa copulatrix is found between the 82nd and the 85th hundredths of the length of the posterior segment. The common genital canal does not traverse a genital cone.

The first testis is asymmetrically developed, largely ovoid to claviform, and placed laterally behind the ovary; it measures 270 to $305 \mu$ in the longitudinal dimension, and 305 to $315 \mu$ transversely. The second testis is clearly bilobed (with a posierior median indentation), and reaches 420 to $440 \mu$ in transverse diameter; that of the two lobes which occupies the field of the first testis is smaller, measuring but 225 to $250 \mu$ long; the other reaches 270 to $305 \mu$ in length. The anterior border of the first testis is situated between the 21 st and the 25th hundredths of the length of the segment; the posterior border of the second between the 66th and the 69th hundredths.

Host.-Buteo jamaicensis borealis (Gmelin).

Habitat.-Small intestine.

Distribution.-Greenville, Ohio. 
Type.-Deposited in the collection of the Institut de Zoologie, Universite de Neuchâtel.

The new species is related to 7 other neodiplostomes described as parasites of different buteonine birds, and of which one of the common and significant characters is furnished by the first, asymmetrically developed, claviform testis, which is situated more or less laterally. If one should judge them by the brief original description of von Linstow (1906), it nearly resembles $N$. attenuatum, which is distinguished from it by the limit of the vitelline glands $(33 / 100$ to the length of the anteror segment), situated well in advance of the ventral sucker $(53 / 100)$.

With N. krausei Dubois, 1937, this limit coincides indeed with the frontal border of the acetabulum, but the worm is two times smaller; the ventral sucker is found between the 54th and 62nd hundredths of the length of the anterior segment, which reduces to $60 \mu$, at the most, the distance from its posterior border to the front of the tribocytic organ. In N. pseudattenuatum (Dubois, 1928), the cylindrical posterior segment is subequal to the anterior segment, of which the second half, or even the last 3/5 are in the main occupied by the tribocytic organ; the vitelline follicles extend beyond the ventral sucker (situated betwecis the 40th and the 46th hundredths of the length of the segment). It is the same, in regard to the extension of the vitelline glands in $N$. inaquipartitum Dubois, 1935, but the acetabulum is placed at the center of the anterior segment which is $13 / 5$ to 2 times longer than the ovoid posterior segment, and of which the last $2 / 5$ constitute the zone of the tribocytic organ. These four species are European.

With N. rufeni Chatterji, 1942, found in India, the posterior segment is longer than the anterior, and the suckers are subequal between them. ${ }^{7} \mathrm{~N}$. biovatum Dubois, 1937, which is Brasilian, is distinguished from its congeners by the feeble transverse constriction of its body, and by the fact that the oral sucker is the same size, or often slightly larger than the ventral sucker, which is surpassed by the vitelline follicles. Among North American forms parasitic in diurnal raptors, only $N$. paraspathula Noble, 1936, is known at present, of which the total length and the proportion of the segments of the body correspond well enough to those of the new species, but the advance of the vitelline glands suffices to distinguish it.

\section{Posthodiplostomum Minimum (MacCallum)}

Some examples of this species, to which M. S. Ferguson has devoted much study, were found associated with Apharyngostrigea cornu (Zeder), menticned above, and collected from a specimen of Ardea herodias L. (host num. ber 3), captured at Buckeye Lake, Ohio, May 16, 1944. One among them, because of its size, surpasses anything that has been observed up to now: total length $1.59 \mathrm{~mm}$; length of posterior segment $0.54 \mathrm{~mm}$; of the anterior segment

7 Neodiplostomum rufeni has to be placed in the subgenus Neodiplostomum, and not in Conidioplostomum, as Chatterji (1942, p. 25) claimed. The error in attribution arose in that the author considered as "genital cone" (fig. 2) a portion of the thick posterior wall of the bursa copulatrix, isolated in appearance (in the sagittal section) by the opening effected by the common genital canal in arriving in the "genital atrium." 
$1.05 \mathrm{~mm}$; ratio of these last two dimensions $=0.51$. Width of the anterior segment in its first half is $0.57 \mathrm{~mm}$, and at the level of the tribocytic organ $0.47 \mathrm{~mm}$; width of the posterior segment $0.42 \mathrm{~mm}$. Diameter of the oral sucker 45 by $52 \mu$; of the pharynx 29 by $31 \mu$; of the ventral sucker 81 by 89 $\mu$; and of the tribocytic organ 190 by $145 \mu$.

The anterior limit of the vitelline follicles is found between the 51st and the 54th hundredths of the length of the first segment, whereas the ventrai sucker is situated there between the 64th and the 66th hundredths. Thus, the follicles pass by $100 \mu$ the level of the frontal border of the last; as with $P$. cuticola (von Nordmann), of Europe, and with $P$. australe Dubois, of Australia, they are restricted in a field having almost the same width as the second evoid segment, in which they are extended ventrally up to the height of the posterior border of the second testis.

\section{Uvulifer semicircumcisus n. sp.}

Many examples of this worm were collected from the intestine of a specimen of Megaceryle alcyon (L.) (host number 4), shot on August 10, 1946, at Pte. Mouillee, Michigan.

The total length of the body is from 1.66 to $1.86 \mathrm{~mm}$. The oval anterior segment, cochleariform and projecting ventrally at the posterior border, measures 0.39 to $0.52 \mathrm{~mm}$ long, by 0.27 to $0.32 \mathrm{~mm}$ wide, and 0.13 to $0.20 \mathrm{~mm}$ in maximum height posteriorly. The tribocytic organ, of which the antero-posterior diameter reaches 0.12 to $0.17 \mathrm{~mm}$, shows up in its concavity. The posterior segment, inserted at the dorsal face of the preceding, is cylindrical or claviform, and arched chiefly at the neck, which is more narrow. This explains why all the specimens were mounted on the side. The posterior segment measures 1.26 to $1.62 \mathrm{~mm}$ long, and 0.27 to $0.40 \mathrm{~mm}$ in dorso-ventral diameter, of which the maximum is at the height of the testes. Its posterior extremity, less wide and rounded, appears obliquely truncate by examination of the profile, by the fact that the terminal genital pore is oriented dorsally. The ratio of the length of the posterior segment to that of the anterior segment is 2.54 to 3.25 .

At the attenuated extremity of the anterior segment, the oral sucker pro-

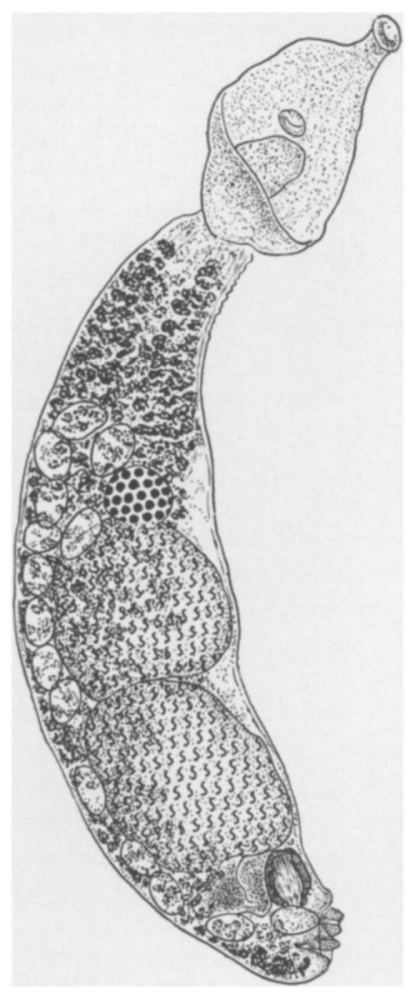

Fig. 14. - Uvulifer semicircumcisus n. sp., from Megaceryle alcyon (L.). Length: $1.78 \mathrm{~mm}$. 
trudes, measuring 48 to $65 \mu$ in length, and 60 to $80 \mu$ transversely. The mediocre state of preservation of this part of the body did not permit us to indicate the dimensions of the pharynx, seen only in a single individual. The ventral sucker, situated immediately in front of the tribocytic organ, being a little near to the middle of the length of the anterior segment, is but 40 to 49 1 . in diameter.

The spherical ovary is found between the $32 \mathrm{nd}$ and the $42 \mathrm{nd}$ hundredths of the length of the second segment (average 35/100). Its diameter is from 108 to $120 \mu$. The vitelline glands occupy all the posterior segment, extending from one extremity to the other, without interruption. They reveal only the two testes laterally, and mask the bursa copulatrix. The vitelline reservoir is intertesticular. The eggs, numbering from 1 to 20 in the uterus, measure 80 to $102 \mu$ by 53 to $67 \mu$ (average: 92 by $60 \mu$ ).

With the bursa copulatrix the massive, unlobed, ovoid or ellipsoid testes occupy the last $3 / 5$ of the posterior segment; the second is always longer than the first, and compresses the seminal vesicle between the terminal part of the uterus and the ejaculatory pouch. The dimensions of the anterior testis are: 260 to $350 \mu$ in length by 180 to $300 \mu$ dorsoventrally (average: 285 by 245 $\mu$ ); those of the posterior testis: 290 to $400 \mu$ by 200 to $295 \mu$ (average: 359 by $242 \mu$ ). The ejaculatory pouch is situated dorsally; it measures 90 to $120 \mu$ long by 63 to $85 \mu$ wide; its walls, 8 to $25 \mu$ thick, appear strongly muscled. It empties directly into the uterus, which approaches it near the outflow channel, curving dorsally to become, at the point of confluence, the short common genital canal, which traverses the genital cone. The latter is sheltered in the bursa copulatrix, 72 to $100 \mu$ deep. This thick-set cone, 45 to $60 \mu$ high, is directed parallel to the longitudinal axis of the body, in the prolongation of the excretory pouch itself. It is enveloped ventrally by an exsertable coil, in the form of a rounded and concave small strip, 60 to $70 \mu$ long, and 15 to $22 \mu$ thick, which is rooted at its base. This coil is applied on its side and scarcely projects over its top - a kind of a semi-prepuce on oblique section, homologous to the "genital bulb" described in the other congeneric species (fig. 15).

Host.-Megaceryle alcyon (L.).
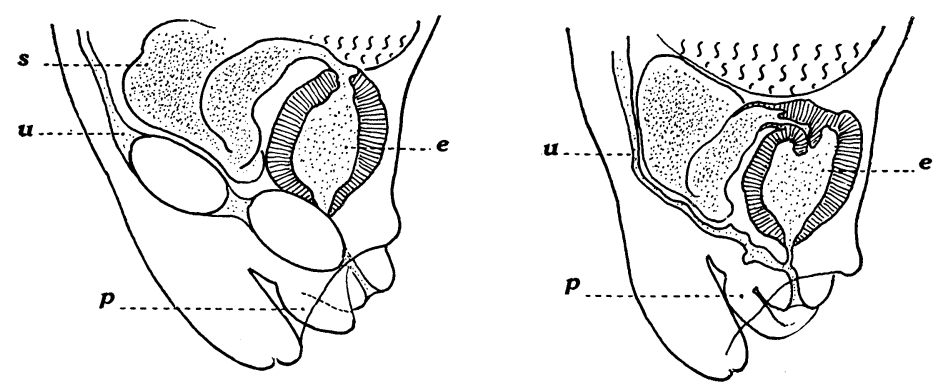

Fig. 15.-Uvulifer semicircumcisus n. sp., from Megaceryle alcyon (L.). Schematic drawing of the posterior extremity of the body. 
Habitat.-Small intestine.

Distribution.-Pte. Mouillee (Lake Erie), Michigan.

Tvpe.-Deposited in the collection of the Institut de Zoologie, Université de Neuchâtel.

This new species is distinctly differentiated by its very dimensions from $U$. dent:culatus (Rudolphi) (Europe), from $U$. cochlearis (Verma) (India), and from $U$. prosocotyle (Lutz) (Brasil). It can not be confused with $U$. gracilis Yamaguti (Japan), of which the genital glands only occupy the last third or the last fourth of the posterior segment, which is deprived of vitelline follicles up to $1 / 6$ or to $2 / 5$ of its length. It is also differentiated from $U$. ceryliformis (Vidyarthi, 1938) Bhalerao, 1942, which has no ventral sucker. It approaches, on the contrary, $U$. ambloplitis (Hughes) (United States), but differs from it by the fact that the second testis is always longer than the first, and by the maximum extension of the vitelline follicles into the posterior segment. 8

\section{Uvulifer magnibursiger $n$. sp.}

Three examples of this species were found among specimens of $U$. semicircumcisus, taken from the same host specimen.

The total length of the body is 2.19 to $2.75 \mathrm{~mm}$. The oval, anterior, cochleariform segment measures 0.45 to $0.48 \mathrm{~mm}$ long, by 0.21 to $0.24 \mathrm{~mm}$ wide; its posterior edge resembles a sigmoid valvule, being incurved ventrally to the height of the tribocytic organ. This has been distinctly seen on but one specimen, where it had an elliptical contour, with a large, transverse axis of $125 \mu$, and a small longitudinal axis of $98 \mu$; its center was situated at the 66 th hundredth of the length of this part of the body. The claviform posterior segment begins with a narrow neck (90 to $170 \mu$ in diameter), followed by an inflated part, occupied by the genital glands, and which contracts slightly up to the beginning of the spacious bursa copulatrix, delimited by a feeble constriction; it measures 1.71 to $2.25 \mathrm{~mm}$ in length, and presents its maximum width at the level of the first testis $(0.34$ to $0.42 \mathrm{~mm})$. The attenuated extt emity of the segment $(0.21$ to $0.24 \mathrm{~mm}$ in diameter $)$ is rounded, except if the copulatory apparatus is evaginated, in which case it is dilated $(0.33 \mathrm{~mm}$ in diameter) and conical, with an oblique truncation (fig. $17 \mathrm{~B}$ ). The genital pore is subterminal, oriented at the dorsal side. The ratio of the length of the posterior segment to that of the anterior segment is 3.56 to 4.33 .

As with the congeneric species, the oral sucker, measuring 53 to $64 \mu$ long, by 85 to $91 \mu$ wide, always larger than the acetabulum, projects at the extremity of the body. It is provided with a nearly spherical pharynx, of which the dimensions are 43 to $45 \mu$ antero-posteriorly and 41 to $50 \mu$ transversely. The ventral sucker, situated at the 56th hundredth of the length of the segment (observed in only a single specimen) has a diameter of 35 to $38 \mu$.

8 We have not received the work of Pande, where Uvulifer stunkardi (Pande, 1938) Bhalerao, 1942, is described. 
The ellipsoidal ovary is situated at the mid-length of the posterior segment (45/100 to 55/100); it measures 105 to $135 \mu$ in the longitudinal dimension, and 125 to $153 \mu$ in width. The vitelline glands begin toward the middle of the neck, and extend to just in front of the bursa copulatrix, which is always exposed. The vitelline reservoir is inter-testicular. The single egg seen in the uterus measured 95 by $66 \mu$.

The rounded, unlobed testes are equal. The first, of which the anterior margin is situated between the 47th and the 57th hundredths of the length of the segment, measures 225 to $260 \mu$ long, by 270 to $295 \mu$ wide; it is contiguous with the second, of which the posterior margin is located between the 75th and the 83rd hundredths of its length, and of which the dimensions are 225 to 270 $\mu$ by 270 to $285 \mu$. The seminal vesicle is continued by a dorsal ejaculatory pouch, $160 \mu$ long by $100 \mu$ wide, with a thick wall of 15 to $25 \mu$. The common genital canal traverses a genital cone concealed by a very muscular bursa copulatrix, 315 to $325 \mu$ long, ovoid at the time the cone is retracted (itself having a height of $100 \mu$ and a diameter of 80 $\mu$ at the base, cf. fig. $17 \mathrm{~A}$ ), and a depth of 135 to $180 \mu$, according to whether one measures it from the dorsal lip, or from the ventral lip of the sexual pore. On the contrary, when the genital cone is evaginated (having a height of $160 \mu$, and a diameter of $145 \mu$ at the base, cf. fig. $17 \mathrm{~B}$-it appears then to be enveloped ventrally by a prepucial fold 160 to $180 \mu$ high, by 45 to $50 \mu$ in thickness, comparable to that of $U$. semicircumcisus), the bursa copulatrix $245 \mu$ deep, opens wide, allowing the dilated summit of the organ to project, of which non-exsertile part, retained in the extrabursal parenchyma, forms a muscular spherical mass, very apparent and of a

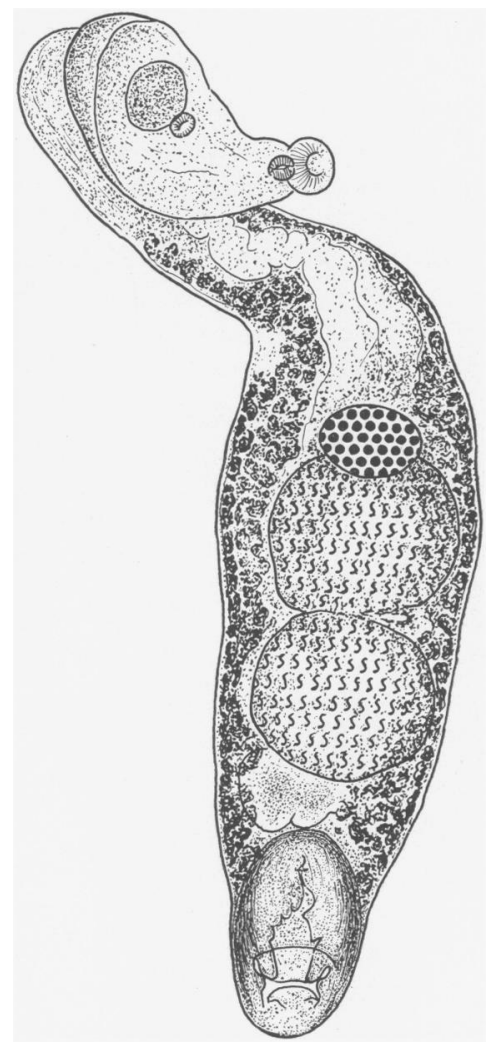

Fig. 16. - Uvulifer magnibursiger n. sp., from Megaceryle alcyon (L.). Dorsal view of posterior segment. Length: $2.19 \mathrm{~mm}$. diameter of $160 \mu$.

This species is distinguished from its congeners by the excessive development of the copulatory apparatus.

Host.-Megaceryle alcyon (L.).

Habitat.-Small intestine.

Distribution.-Pte. Mouillee (Lake Erie), Michigan. 
Type.-Deposited in the collection of the Institut de Zoologie, Université de Neuchâtel.

Note on the genus Uvulifer Yamaguti.-This genus was established for a single species, $U$. gracilis Yamaguti, 1934. According to the describer, the genotype is characterized essentially by the presence of an "uvula-like muscular appendage," situated in the bursa copulatrix. We believed we had found this uvuliform organ in Hemistomum denticulatum (Rud.), which we consequently attributed to the genus $U v$ vulifer (cf. Dubois, 1937c, p. 126; 1938, pp. 322 325 and fig. 219). The observations made on the two new species, described above, have led us to re-undertake the examination of $U$. denticulatus (Rud.), collected by Fuhrmann, and deposited in our collection.

We have seen that the genital cone was also half enveloped by a prepucial fold, ventrally disposed; this, in optical section, has indeed the appearance of an uvula, and by analogy, of the structure with an homologous formation and characteristic of Cotylurus Szidat, we have called it "genital bulb." Moreover, in considering the figure 223 of the Monographie des Strigeida, representing the posterior extremity of $U$. prosocotyle (Lutz), we confirm that a prepucial fold has been observed, although we had not mentioned it as such, not being able to furnish at the moment (1938) an adequate interpretation of this anatomical peculiarity. It is probable that the other congeneric species possess likewise this fold, rather than a "bulb."

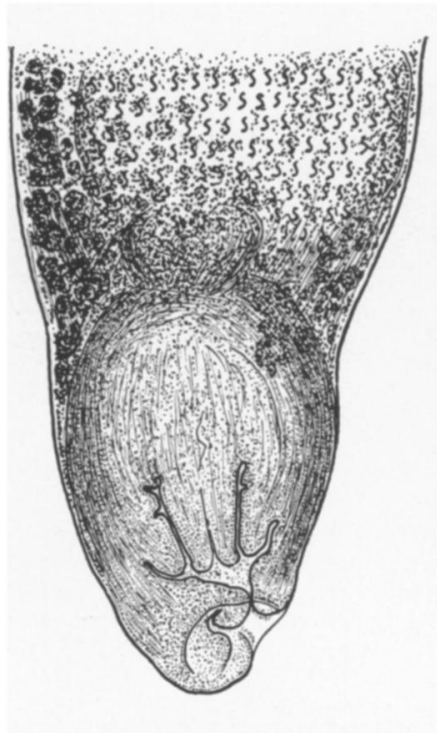

A

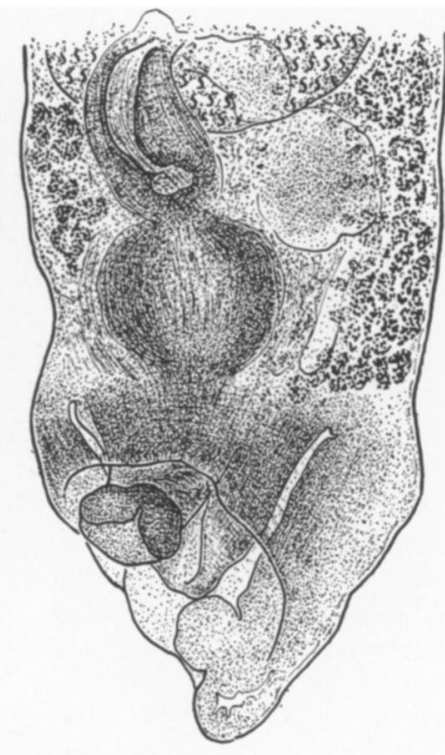

B

Fig. 17.-Uvulifer magnibursiger n. sp., from Megaceryle alcyon (L.). A) Bursa copulatrix retracted. B) Bursa copulatrix expanded. 
This exposition constitutes a new justification of the idea of a derivation of the genus Uvulifer Yamaguti beginning with Posthodiplostomum Dubois (cf. Dubois, 1944, pp. 84-86, and diagram 3). In fact, all the representatives of this last genus possess a protractile bursa copulatrix, of which the fold of the retractile walls constitutes a prepuce completely surrounding the genital cone. Now, the evolutionary process, attested by the progressive retreat of the anterior limit of the vitelline glands which tend to, and finally succeed in confining themselves to the posterior segment, would have obtained at the same time the reduction of the preputial cylinder of the dorsal side.

\section{ADDENDUM}

\section{Diplostomum micradenum (Cort and Brackett)}

This worm was experimentally obtained by Olivier (1940) in the domestic pigeon, from the larva Cercaria micradena Cort and Brackett, 1938, harbored by Stagnicola palustris elodes (Say), and developing into a diplostome in the central nervous system of the tadpole of Rana pipiens $\mathrm{Gm}$. The exceptional quality of the original material and of its staining leads us to reveal one of its aspects.

The adult measures, according to Olivier, 10.4 to $1.35 \mathrm{~mm}$ in total length (average: $1.15 \mathrm{~mm}$ ). The specimen which we represent has precisely this average dimension. Its width, in front, attains $0.51 \mathrm{~mm}$. The bisegmentation of the body is marked by but a feeble transverse constriction, or, as it is in the case of this example, by a perceptible diminution of the width of the body (see also Olivier, pl. I, fig. 12). Thus delimited, the anterior segment, "round to oval, concave ventrally" is slightly shorter than the hind-body." Our drawing shows its strong concavity - the posterior border concealing a good part of the tribocytic organ.

The ventral sucker ( 95 by $112 \mu$ ), situated rather near the middle of this segment, is larger than the oral sucker ( 95 by $97 \mu$ ); but as Olivier remarked (pp. 457-458), its antero-posterior diameter $(80 \mu)$ is equal to that of the oral sucker. The pharynx measures here 75 by $65 \mu$; the median ovary, 70 by $120 \mu$; the first testis, asymmetrically developed, resembling in shape a shoe, 190 by $260 \mu$; the second testis, of which the posterior border is situated at the 63rd

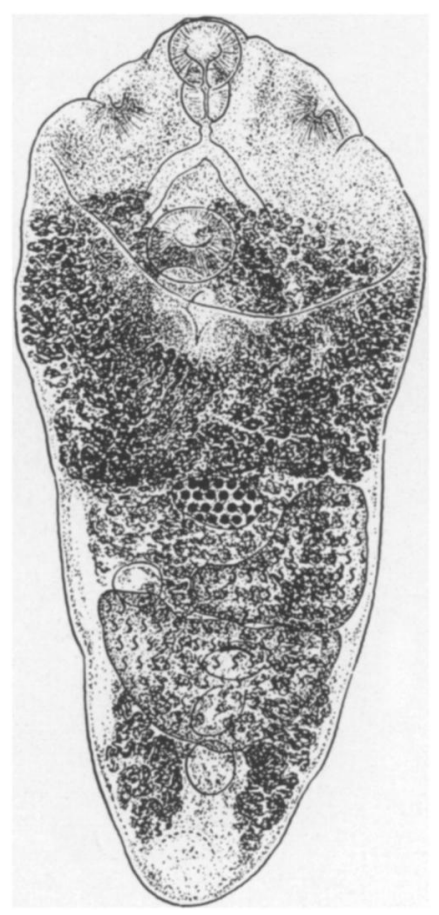

Fig. 18. - Diplostomum micradenum (Cort and Brackett), from the pigeon (type material, U.S. N. M.. Helm. Coll., no. 36701). Length: $1.15 \mathrm{~mm}$. 
hundredth of the length of the segment, 160 to $180 \mu$ by $305 \mu$.

The vitelline follicles have their maximum density in the anterior segment, where they extend hardly beyond the ventral sucker (limit to the 42/100). From the beginning of the posterior segment, they are less abundant, covering the ventral face and forming two lateral masses behind the second testis; these terminate at the height of the curved border of the dorsal and subterminal genital pore. In considering the rather abrupt change of density of the follicles at the intersegmentary level, one finds that the posterior segment is, to the contrary of what has been said, slightly shorter than the anterior. The uterus contained 3 or 4 eggs, not measurable.

\section{REFERENCES}

Bhalerao, G. D. 1942-On Strigeida (Trematoda) from India. Rec. Ind. Mus. Calcutta, 44: 207-216.

BitTnER, H. 1927-Parasitologische Beobachtungen. Z. InfektKr. Berlin, 30: 213-227; 8 figs.

BYkD, E. E. AND J. W. WARD 1943-Notes on the genital system of the bird fluke, Apharyngostrigea cornu (Zeder). J. Parasit. Urbana, 29: 270-274; 3 figs.

Caballero, E. 1944 -Neodiplostomum paraspathula Noble, 1936 (Trematoda: Diplostomidae) en una aguila de Mexico. Anales Inst. Biologia Mexico, 15: 47-52; 3 figs.

Chatterji, R. C. 1942-Studies on the six new species of the genus Neodiplostomum Railliet, 1919 (family Diplostomidae Poirier, 1886). Part I.-New species of the subgenus Neodiplostomum Dubois, 1937. Proc. Nat. Acad. Sci. India, 12: 14-22; 3 figs.

Crurea, I. 1927-Contribution à l'étude morphologique de Sirigea cornu (Rud.). Bull. sect. sci. Acad. roumaine, 11: 12-16; pls. 1, 2.

1930-Contribution à l'étude morphologique et biologique de quelques Strigéidés des Oiseaux ichtyophages de la faune de Roumanie (Recherches expérimentales). Arch. roumaines Pathl. expér. Microbiol., 3: 277-323; pls. $1-17$.

Dubois, G. 1928-Descriptions de nouveaux Trématodes d'Oiseaux de genre "Hemistomum." Bull. soc. neuch. Sci. nat., 52: 33-44; 4 figs.

-1934-Contribution à l'étude des Cercaires de la region de Neuchâtel, suivie d'une note sur les Cercaires du Lac Noir (Zermatt). Rev. Suisse Zool. Genève, 41: 73-84; 6 figs.

-1937a-Sur quelques Strigéidés. Rev. suisse Zool. Genève, 44: 391-396.

1937b-Etude de quelques Strigéidés d'Australie et notes sur le genre Fibricola Dubois, 1932. Ann. Parasitol. Paris, 15: 231-247, 333-353; 22 figs.

-1937c-Contribution à l'étude des Diplostomes d'Oiseaux (Trematoda: Diplostomidae Poirier, 1886) du Musée de Vienne. Bull. Soc. neụch. Sci. nat., 62: 99-128; 14 figs.

1938-Monographie des Strigeida (Trematoda). Mem. Soc. neuch. Sci. nat., 6: 1.535; 354 figs.

1944-A propos de la spécificité parasitaire des Strigeida. Bull. Soc. neuch. Sci. nat., 69: 5.103; 14 tab., 3 diagrs., 2 figs.

Dujardin, F. 1845-Histoire naturelle des Helminthes ou Vers intestinaux. XVI+654 +15 pp.; 12 pls. Paris.

Guberlet, J. E. 1922-Three new species of Holostomidae. J. Parasit. Urbana, 9: 6-14; pls. $4,5$.

IU nter III, G. W. 1933-The strigeid Trematode, Crassiphiala ambloplites (Hughes, 1927). Parasitology, Cambridge, 25: 510-517; 6 figs. 
KRULL, W. H. 1934-Neodiplostomum pricei n. sp., a new Trematode from a Gull, Larus novaehollandiae. J. Wash. Acad. Sci., 24: 353-356; 2 figs.

Lrvtz, A. 1928-Estudios de Zoologia y Parasitologia Venezolanas. 133 pp.; 26 pls. Rio de Janeiro.

Mathias, P. 1925-Recherches expérimentales sur le cycle évolutif de quelques T́rématodes. Bull. biol. France et Belgique, 59: 1-123; pls. 1-4.

Mirller JR., H. M. 1927-Furcocercous larval Trematodes from San Juan Island, Washington. Parasitology, Cambridge, 19: 61-83; 3 figs., pls. 3, 4.

NAZMi (Gohar), M. 1935-Liste des Trómatodes parasites et de leurs hôtes vertébrés signalés dans la vallee du Nil. IIe. partie. Ann. Parasitol. Paris, 13: 80-90.

Noble, A. E. 1936-New avian Trematodes of the genus Neodiplostomum. J. Parasit. Urbana, 22: 247-254; 7 figs.

Olivier, L. 1940-Life history studies on two strigeid Trematodes of the Douglas Lake region, Michigan. Ibid., 26: 447-477; pls. 1-3.

Olsen, O. W. 1940-Two new species of Trematodes (Apharyngostrigea bilobata; Strigeidae, and Cathaemasia nycticoracis: Echinostomidae) from Herons, with a note on the occurrence of Clinostomum campanulatum (Rud.). Zoologica, New York, 25: 323-328; pl. 1.

Rudolphi, K. A. 1809-Entozoorum sive Vermium intestinalium. historia naturalis. Amstelaedami. 2 (1), 457 pp.; pls. 7-12.

SkrJabin, K. I. 1928-Sur la faune des Trématodes des Oiseaux de Trans-baikalie. Ann. Parasitol. Paris, 6: 80-87; 2 figs.

Stunkard, H. W., C. H. Willey, and Y. Rabinowitz 1941-Cercaria burti Miller, 1923, a larval stage of Apatemon gracilis (Rudolphi, 1819) Szidat, 1928. Trans. Amer. Micr. Soc. Menasha, 60: 485-497; pls. 1-2.

SzIDAT, L. 1929-Beiträge zur Kenntnis der Gattung Strigea (Abildg.) I. Allgemeiner Teil: Untersuchungen über die Morphologie, Physiologie und Entwicklungsgeschichte der Holostorniden nebst Bemerkungen über die Metamorphose der Trematoden und die Phylogenie derselben. II. Spezieller Teil: Revision der Gattung Strigea nebst Beschreibung einer Anzahl neuer Gattungen und Arten. Z. Parasitenk. Berlin. 1: 612-764; 35+35 figs., 8 pls.

-1929b-Beiträge zur Entwicklungsgeschichte der Holostomiden III. Ueber zwei Tetracotylen aus Hirundeen und ihre Weiterentwicklung in Enten zu Cotylurus cornutus Rud. und Apatemon gracilis Rud. Zool. Anz. Leipzig, 86: 133-149; 8 figs.

Timon-David, J. 1943-Sur la présence en Camargue et le développement expérimental de Cotylurus cornutus (Rud.) (Trématode, Strigéidé). Bull. Mus. Hist. nat. Marseille, 3: 17-21; 1 fig.

Vidyarthi, R. D. 1938-New avian Trematodes (family Diplostomidae) from Indian birds. Proc. Nat. Acad. Sci., India, 8: 76-84; 4 figs.

Vigueras, I. P. 1944-Trematodes de la super-familia Strigeoidea; descripcion de un genero y siete especies nuevas. Universidad de la Habana, $\mathrm{n}^{\circ}$. 52-53-54, pp. 293. 314; figs. 1-16.

Yamagutr, S. 1933-Studies on the helminth fauna of Japan. Part I. Trematodes of Birds, Reptiles, and Mammals. Japan J. Zool. Tokyo, 5: 1-134; 57 figs.

- 1934-Studies on the helminth fauna of Japan. Part 3. Avian Trematodes, II. Ibid., 5: 543-583; 16 figs. 